\title{
PARKING OCCUPANCY DETECTION USING IOT
}

\author{
Devan Hariharan \\ Computer Science and Engineering \\ Mar Baselios Institute of Technology and Science \\ Kothamangalam, India \\ Vishwas Krishna AR \\ Computer Science and Engineering \\ Mar Baselios Institute of Technology and Science \\ Kothamangalam, India
}

\author{
Rahul Krishnakumar MC \\ Computer Science and Engineering \\ Mar Baselios Institute of Technology and Science \\ Kothamangalam, India \\ Susanna M Santhosh \\ Computer Science and Engineering \\ Mar Baselios Institute of Technology and Science \\ Kothamangalam, India
}

\begin{abstract}
- one of the major challenges faced by busy cities is traffic congestion. Parking vehicles in a traffic dense environment is time consuming and fuel wastage, the driver may loss time by driving in search for free space which ends up in congestion and increases the environmental pollution. Lack of information of vacant parking spaces is one reason for inefficient parking behavior. Smart parking sensors and machinery facilitate guidance of drivers to free parking spaces thereby improving parking order. Currently, no such sensors or technologies are in use for open parking lot. Ultrasonic sensors and machine vision were few of the extensively used sensors and technologies on closed parking lots. As the number of vehicles keeps on increasing an efficient parking system must be implemented. As a solution this paper aims to set up a Smart Parking System by using technologies like Internet of Things. This system helps to find the parking slots with real-time data being stored in cloud, we also build an android application which shows all the details of the parking lots in the city and free spaces present there. Using this application the user can prebook a parking space in their desired location if there is empty parking space available. This reduces time loss in search for parking space and also decreases the air pollution. Also another main feature of this application is that people with large space can register their place in it, which can be used as parking ground using our technology. This will be very helpful in times of sudden demand for parking spaces the nearby people can register their grounds to our application and the people visiting can park their vehicles in the spaces available.
\end{abstract}

\section{Keywords—iot, aduino, NodMCU, Ultrasonic sensors}

\section{INTRODUCTION}

The amount of automobiles is explosively increasing and finding a vacant parking slot are very stressful in densely inhabit area Often the driver need to search for parking space circling around parking lots which result in more fuel consumption, increases anxiety in drivers and can even cause accidents. Many Studies suggest that $5-10 \%$ of road accidents are caused in the time of searching for parking spaces. Today parking has become an alarming issue in almost of all cities. One of the major causes is unavailability of parking areas and increasing number of vehicles adds more traffic congestion which makes the situation worst. The scarcity of unoccupied parking area is noticeable in most public places like markets, hospitals, airports and so on. This situation gets even more complicated especially during peak times like a festival or a tourists season in most of the cases large numbers of vehicles compete with few unoccupied parking spaces. Most of the time is wasted on searching vacant slot in car parks which causes traffic jam. This leads air pollution caused by the cars in halt both in indoor and outdoor car parks. As we are living in a fast moving world most of the people use their own vehicles which in turn increase the effort of finding parking spaces for the drivers. So we need a smart parking system that reduces the searching time, traffic congestion and road safety. This system helps the drivers to inform the vacant spaces in and around the desired destination in advance. Solution might be a choice network that uses smart parking sensor and technologies to detect parking occupancy information which facilitates the drivers to make informed decision of where to travel and park their car. Internet of things or IOT is the best solution for smart parking system. Therefore to overcome the problems we propose smart parking using sensors and similar technologies. Many studies and parking system uses fog computing and similar technologies which costs more money for installation and maintenance. Also most of the smart parking studies simply focus on parking a vehicle without using much of IOT. Using IOT there is a whole new level of smart parking strategies we can bring up in a cost effective way. The present study proposes a low cost IOT based parking solution which not only focus on simple parking of a vehicle but also brings an innovative idea of building temporary 
parking slots in time of a festival or similar purpose. Each parking lot is considered as an IOT network and the main data's included in our system are GPS location, nearby parking slots available and amount of vacancies available there etc. The main goal of our paper or our Aim is to improve the parking rate, Provide services of better quality and to sufficiently utilize all the features and benefits of IOT. The reservation is possible with the help of sensors which are subjected to environmental conditions when placed outdoors. Therefore, aptness of sensors and technologies was made by compatibility and outlay parameters.

\section{EXISTING SYSTEM}

One of the major problems of many large and busy cities is the inefficient parking systems, finding a vacant space for parking is very difficult. The conventional method of finding a parking space is completely done manually. The drivers themselves have to search for the vacant parking slot at or near the desired destination. This process is too time consuming and also leads to traffic congestion. The poor maintained parking areas may even reduce the road safety not only that unwanted fuel combustion is the one of the reasons behind air pollution. As the population of vehicles keeps on increasing the current scenarios will get even worse unless we introduce a proper efficient parking system

\section{PROPOSED SYSTEM}

Our proposed system consists of a mobile application which will have all the details of the parking slots in the desired city. The user will have to login to the application and once logged in the application will show the nearby empty parking spaces available in the city. We are using internet of things or IOT. IOT is a system consisting of many computing devices which uses Mechanical and digital machines provided with an identifier and the ability to transfer data over the network without requiring human interaction. All the parking spaces are connected to our web server. Also the key feature of our proposed system is that people can temporally register their land or space for parking purposes. This will be very much helpful in times of festivals or similar situation. Suppose there is a religious festival happening and people coming from different place can book their parking space for a required time. The benefits of using our system are it reduces the pollution which is caused in search of parking space, also it reduces anxiety in drivers and thus further reduces accidents causing while in search for parking.

\section{A. Method}

This focuses on sensors, technologies and interfaces which are used to collect and display real-time parking occupancy information. The suitability of sensors and technologies is made in terms of compatibility and expenditure. Since, the majority of open parking lots are placed outdoors; compatibility is measured in terms of varying environment and lighting conditions while expenditure is measured in terms of purchase cost, installation and maintenance. In existing smart system parking meters which are hold for payments are placed either at a parking lot or beside parking spaces. We have a mobile application for the booking and parking related activities. However, here parking applications which give real time parking occupancy information and navigational directions to a reserved parking zone are selected. All the referred applications support booking which is possible only in vacant parking lots. Smart parking applications also provide navigational directions to the reserved parking lot.

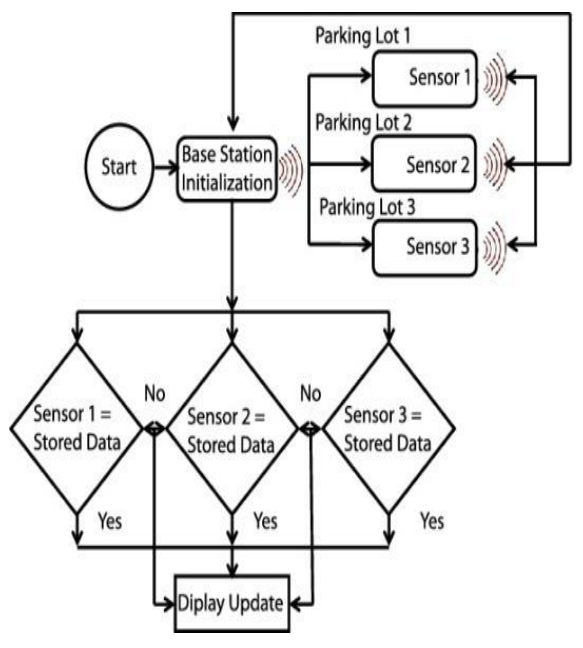

Fig 1: Work flow chart

\section{B. Tools}

Smart parking tools contain sensors, technologies and mobile applications which are used to identify parking occupancy information and used to improve parking efficiency. Machine vision using visual camera and sensors benefits the reservation process. Sensors like ultrasonic are widely reviewed and tested which are utilized in various smart parking applications. Here we use arduino and sensors for the execution of this system.

\section{Smart parking sensors}

There are various sensors which facilitate in detecting parking occupancy information and these are used widely in our market. Sensors are one of the common tools which were widely tested in several previous departments and studies. Descriptions of these sensors are mentioned:

\section{1) Ultrasonic sensor}

These sensors send ultrasonic sound waves between 25 and $50 \mathrm{kHz}$ to detect objects in front of them and it will be reflected back if object is present. They are usually mounted on the ceiling or placed at the backside of an open parking 
space and are sensitive to environmental changes like rain and snow. Therefore, they're suitable for indoor parking lots rather than open parking lots because it can get effected due to various climatic conditions. In simple words it calculates the distance between a target object from the sensor by emitting ultrasonic sound waves and this wave on reflecting is converted to an electric signal. In order to obtain accurate parking occupancy status, these sensors should be placed on top of every parking spaces. These sensors are available for low cost in the market but installation and maintenance of multiple sensors and connecting them to a grid for accuracy would be expensive. These sensors are used widely due to its accuracy and its efficient working in various climatic conditions.

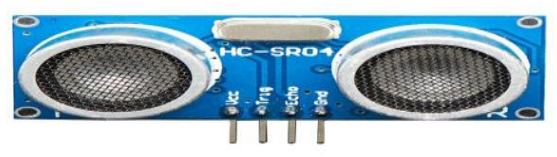

Fig 2: Ultrasonic sensor

\section{2) Arduino Uno}

The Arduino Uno developed by Arduino is based on Microchip ATmega328P microcontroller. This open source microcontroller board contains sets of digital and analog input and output $(\mathrm{I} / \mathrm{O})$ pins. These pins for its easy functioning are interfaced to various expansion boards and circuits. The board developed by Arduino has 14 digital Input/Output pins, 6 analog I/O pins. Another feature of this microcontroller board is that it is programmable with the Arduino IDE, with a type B USB cable. It is powered by the use of a USB cable. However it can also be powered by batteries of small volts, as it accepts voltages between 7 and 20 volts for its functioning. It has got many similarities with Arduino Nano and Leonardo. Original STK500 protocol is used by this microcontroller board for its communication. There are many differences with the other boards similar to Uno as it does not use the FTDI USB driver chip. The Microcontroller board Arduino Uno uses the Atmega16U2 programmed for USB to serial converter.

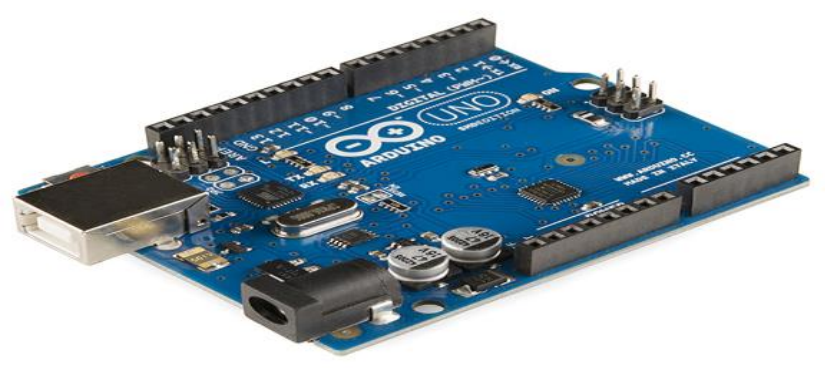

Fig 3: Arduino Uno

\section{Parking guidance systems}

Parking guidance systems is another type of smart parking system which provides information about number of parking lots available on display screens and these are usually placed near the parking lots because the driving force can see and choose the parking lot to occupy. Cameras are used at the doorway of the parking lots and exit of a parking lot to know the count of the vehicles in a parking zone so that it could be displayed on the screens. However, they're not guiding the driver to a selected parking space which is found empty. There's still every possibility that the driver would cruise inside the parking lot for several minutes before finding an empty space to occupy.

\section{1) Global positioning system:}

The navigational directions based on GPS are provided to the drivers for occupying a vacant parking zone from the current position of the driver. GPS will find the shortest or the most appropriate route from the current location. GPS alone doesn't have the capability of gathering information of parking spaces but provides help in showing the location. Parking lots are estimated using many methods and the navigational directions are provided using GPS to the estimated parking lot. The accuracy of the GPS is usually lesser or equal to $7.8 \mathrm{~m}$.

\section{E. Discussions}

Most of the applications don't provide real-time or accurate parking information from the parking zones. Lack of economy is often the reason for not providing real-time occupancy information of open parking lots. As the economic gain is not immediate with the use of smart parking tools at open parking spaces, it will be suitable to use a sensor or technology with minimal expenditure for making it financially viable.

An excellent parking application would assist the driver in providing a choice network and should also help in reducing congestion by showing path with less traffic. However, few drivers won't be convenient in using an application for parking occupancy as they are not familiar with it. The complete benefit of smart parking is achieved if and only if every driver is using the application which isn't practically possible in real world. The sensors and technologies are largely used by most of the parking lots which support reservation in them. Sensors like magnetometers aren't sensitive to environmental conditions because of their covering but are expensive to use and maintain at open parking lots regularly. Infrared sensors on comparing with Ultrasonic are sensitive to environmental conditions which could cause inaccurate parking occupancy information but if carefully maintained they will provide accurate information in less cost similar to UV sensors. Smart Parking Systems are 


\section{International Journal of Engineering Applied Sciences and Technology, 2020 \\ Vol. 5, Issue 1, ISSN No. 2455-2143, Pages 656-659 \\ Published Online May 2020 in IJEAST (http://www.ijeast.com)}

being used nowadays very often and will be used regularly in coming years.

\section{CONCLUSION}

The system we created reduces the gap or effectively utilizes the smart parking sensors and technologies for parking lots. Most of the smart parking technologies present aren't suitable for parking lots because of many technical, physical issues to the sensors and varying environmental conditions. Also due to the high expenditure most system compromise on the quality of hardware used which cost them much further problems in the future. Other than showing the number of available spaces in the parking lot like most applications does the application we built shows the best or shortest parking space near to the destination place given by the user. Also for improving the parking efficiency navigational directions will be shown after the user selects a parking space. We have selected the best hardware in the market to overcome the environment problem. After reviewing each parking lot and its size hardware are selected accordingly to reduce the cost without any compromise to the system as a whole.

\section{ACKNOWLEDGEMENT}

I would like to convey my heartfelt gratitude towards my guide, Mrs. Susanna M Santhosh for her constant guidance, encouraging help and inspiring words. I am thankful to the department of Computer Science and Engineering for their support.

\section{REFERENCE}

[1] Melnyk P, Djahel S and Nait-Abdesselam F.( 2019). Towards a Smart Parking Management System for Smart Cities, in IEEE International Smart Cities Conference(ISC2), (10.1109/ISC246665.2019.9071740).

[2] kilic $\mathrm{T}$ and Tuncer T.( 2017).Smart city application: Android based smart parking system, in International Artificial Intelligence and Data Processing Symposium (IDAP), ( 10.1109/IDAP.2017.8090284)

[3] Kazi S, Khan S, Ansari U and Mane D.(2018). Smart Parking based System for smarter cities, in International Conference on Smart City and Emerging Technology (ICSCET), (10.1109/ICSCET.2018.8537281.

[4] Sadhukhan P.( 2017 ). An IoT-based E-parking system for smart cities, in International Conference on Advances in Computing, Communications and Informatics (ICACCI), (10.1109/ICACCI.2017.8125982) .

[5] Šilar J, Růžička J, Bělinovà $Z, \quad$ Langr $M$ and Hlubučková K.(2018). Smart parking in the smart city application, in Smart City Symposium Prague (SCSP), ( 10.1109/SCSP.2018.8402667)

[6] Krishna Kolli Y and D. Vakula .(2017). Low cost smart parking system for smart cities, in International Conference on Intelligent Sustainable Systems (ICISS), ( 10.1109/ISS1.2017.8389415)

[7] Lin J, Chen S, Chang C and Chen G.(2019). SPA: Smart Parking Algorithm Based on Driver Behavior and Parking Traffic Predictions, in IEEE Access ( Volume: 7 ), ( 10.1109/ACCESS.2019.2904972)

[8] Ebin P.M., Akhil Dev P, Mishab P, Sreejith C and Srudhil U K.(2018). An Andriod Application for Smart Parking With Efficient Space Management, in International Conference on Emerging Trends and Innovations In Engineering And Technological Research (ICETIETR), (10.1109/ICETIETR.2018.8529084)

[9] Ramasamy M, Solanki S G, Natarajan E and Mun Keat T .(2018). IoT Based Smart Parking System for Large Parking Lot, in IEEE 4th International Symposium in Robotics and Manufacturing Automation (ROMA), (10.1109/ROMA46407.2018.8986731)

[10] Ramasamy M, Solanki S G, Natarajan E and Mun Keat T .(2018). IoT Based Smart Parking System for Large Parking Lot, in IEEE 4th International Symposium in Robotics and Manufacturing Automation (ROMA), (10.1109/ROMA46407.2018.8986731)

[11] Ampuni A, Fonataba S, Fitrianto A and Wang G .(2019). Smart Parking System With Automatic Cashier Machine Utilize the IoT Technology, in International Conference on ICT for Smart Society (ICISS), ( 10.1109/ICISS48059.2019.8969793)

[12] Kazi S, Nuzhat S, Nashrah A and Rameeza Q .(2018). Smart Parking System to Reduce Traffic Congestion, in International Conference on Smart City and Emerging Technology (ICSCET)

( 10.1109/ICSCET.2018.8537367)

[13] C, Yi-Lung Lu, Tsai Mand Chang H.(2018). Utilization-based parking space suggestion in smart city, in 15th IEEE Annual Consumer Communications \& Networking Conference (CCNC)

( 10.1109/CCNC.2018.8319281)

[14] Gören S, Óncevarlk D F, Doruk Yldz K and Hakyemez T Z.(2019).On-Street Parking Spot Detection for Smart Cities, in IEEE International Smart Cities Conference (ISC2), ( 10.1109/ISC246665.2019.9071760)

[15] paidi V, Fleyeh H, Hakansson J and Nyberg R G.(2018). Smart Parking sensors, technologies and applications for open parking Lots : a review, in IET Intelligent Transport Systems ( Volume: 12 , Issue: 8, 102018 ), ( 10.1049/ietits.2017.0406) 